\title{
Short Communication: Dominance in Free-Stall-Housed Dairy Cattle Is Dependent upon Resource
}

\author{
D. Val-Laillet, ${ }^{* 1}$ D. M. Veira, ${ }^{*}$ and M. A. G. von Keyserlingkt ${ }^{2}$ \\ ${ }^{*}$ Pacific Agri-Food Research Centre, Agriculture and Agri-Food Canada, 6947 \#7 Highway, PO Box 1000, Agassiz, British Columbia, \\ VOM 1A0, Canada \\ †Animal Welfare Program, 2357 Main Mall, University of British Columbia, V6T 1Z4, Canada
}

\begin{abstract}
The main objective was to assess the consistency in competitive success across 3 common resources available to dairy cows housed in free-stall barns. Specifically, we determined if those cows that displaced other cows most often at the feed bunk (high-ranking) had priority of access to free-stalls or a mechanical brush. Our secondary objective was to determine if the displacements at each resource were a function of usage of that resource. These objectives were tested using 6 groups of 12 lactating dairy cows housed in pens with $0.6 \mathrm{~m}$ of bunk space per cow, 1 free-stall per cow, and 1 mechanical brush per pen. Time-lapse video was used to quantify the time spent feeding, in the stalls, and using the mechanical brush. The incidence of displacements at the feed alley and lying area was measured for $3 \mathrm{~d}$ consecutively. Usage was lower for the brush, so displacements were monitored for $14 \mathrm{~d}$ consecutively. The individual measures of competitive success were not highly correlated between resources indicating a cow that frequently displaced other cows for access to one particular resource did not always do so when accessing the other resources. Competition at the feeder was responsible for $87.6 \pm 1.4 \%$ of displacements observed throughout the experiment, indicating that gaining access to feed was a high priority for cows. These results suggest that competitive success by dairy cows may vary according to each cow's motivation to access the resource.
\end{abstract}

Key words: dairy cow, dominance, competitive success, resource

The intensification of dairy cattle production has resulted in cows being housed at much greater densities than in traditional grazing situations. Although cattle

\footnotetext{
Received May 5, 2008.

Accepted June 18, 2008.

${ }^{1}$ Current address: INRA, UMR1079 SENAH, Domaine de la Prise, F35590 St Gilles, France.

${ }^{2}$ Corresponding author: nina@interchange.ubc.ca
}

engage in some aggressive interactions when kept on pasture (Phillips and Rind, 2001), the number dramatically increases when space constraints are imposed (Orihuela and Galina, 1997; Fregonesi et al., 2007). Much work on social behavior in dairy cattle was focused on how particular management strategies affect aggression within a group. For example, cows compete for access to feeder space (DeVries et al., 2005; Huzzey et al., 2006), to preferred free-stalls (Fregonesi et al., 2007), and other resources within the pen (DeVries et al., 2007). Moreover, when resources become limiting due to overstocking, the frequency of aggressive interactions increases dramatically. For example, cows provided access to $1.0 \mathrm{~m}$ of feeding space per cow engaged in $57 \%$ fewer aggressive interactions while feeding compared with cows provided with access to half this space allowance (DeVries et al., 2004). Cows spend less time lying down and more time standing outside the stall, engage in more aggressive behavior, and take more time to lie down after milking when stocking density in free-stalls increases gradually from 100 to $150 \%$ (Fregonesi et al., 2007).

One researcher working on social behavior categorized individuals within the group according to a linear hierarchy (Drews, 1993) based on the individual's ability to gain access to a particular resource. Nevertheless, others report that competitive order does not always reflect the dominance relationship in a herd (Rushen, 1984; Craig, 1986). Further, some suggested that animals value resources (i.e., feed versus lying areas) differently (Lobato and Beilharz, 1979; Phillips, 1993). Moreover, Soffié et al. (1976) noted that the dominance order based on access to feed was not correlated with order of access to the milking parlor in dairy cows. Unfortunately, many of these studies have been poorly replicated (Phillips, 1993) and primarily limited to one resource (DeVries et al., 2004). Fregonesi et al. (2007) indicated that cows spend approximately $12 \mathrm{~h} / \mathrm{d}$ lying down and approximately $5 \mathrm{~h} / \mathrm{d}$ engaged in feeding activities (DeVries et al., 2003) indicating that they make use of these 2 resources frequently throughout the day. Previously, we have shown that cows prefer- 
entially use a mechanical brush compared with other structures (e.g., railings) when given the opportunity (DeVries et al., 2007), suggesting that this resource is of some value to cows housed indoors.

The main objective was to assess the consistency in competitive success across 3 common resources available to dairy cows housed in free-stall barns. Specifically, we determined if cows that were successful in displacements at the feed bunk that enabled them to gain access to the food also had priority of access to free-stalls or a mechanical brush. Our secondary objective was to determine if the displacements at each resource depended upon the usage of that resource.

Seventy-two lactating Holstein dairy cows were managed according to the guidelines set by the Canadian Council on Animal Care (1993). The animals were divided into 6 groups of 12 cows ( 2 pens $\times 3$ repetitions) balanced for DIM $(41.0 \pm 2.6)$, parity $(3.6 \pm 0.2)$, and milk production $(47.2 \pm 0.7 \mathrm{~kg} / \mathrm{d}$ of milk). Cows within each group were housed together continuously for 3 wk in a naturally ventilated building with no access to pasture, before the start of behavioral recordings. Each experimental pen contained 12 free-stalls deep-bedded with $40 \mathrm{~cm}$ of washed river sand and configured in 3 rows (DeVries et al., 2007). Pens were fitted with an automated mechanical brush (Luna Cow Brush, Lely Industries NV, Maasland, the Netherlands) installed in the crossover alley in front of the water trough. The cows were milked between 0500 and $0530 \mathrm{~h}$ and between 1700 and $1730 \mathrm{~h}$, and fed twice daily (approximately 0600 and $1500 \mathrm{~h}$ ) a TMR formulated to meet the NRC (2001) requirements consisting of $21.5 \%$ grass silage, $14.6 \%$ corn silage, $32.3 \%$ corn/barley, $22.5 \%$ protein mash, $5.6 \%$ alfalfa hay, and $3.5 \%$ grass hay on a DM basis. The composition of the TMR was $46.9 \% \mathrm{DM}$ and contained, on a DM basis, $18.7 \% \mathrm{CP}, 18.5 \% \mathrm{ADF}$, $33.9 \% \mathrm{NDF}, 0.95 \% \mathrm{Ca}$, and $0.5 \% \mathrm{P}$. Cows consumed their feed from a feed alley with access via a pendulous feed-rail and were provided $0.6 \mathrm{~m}$ of feeding space per animal. Water was provided ad libitum.

Behaviors were monitored using 3 video cameras per pen, a time-lapse videocassette recorder, and a video multiplexer. Red lights $(100 \mathrm{~W})$ facilitated recording at night. Hair dye was used to create unique alphanumeric symbols on the back of the cows for use in identification. Feeding and lying were recorded continuously for $3 \mathrm{~d}$. Feeding behavior and stall occupancy of individual cows were scored from video using instantaneous scan sampling once every $10 \mathrm{~min}$. An animal was recorded as feeding when its head was completely past the feed rail and over the feed. Cows were considered to be occupying a stall when lying or standing with at least 2 feet in the stall. The total time spent scratching at the mechanical brush was recorded continuously for every animal for $14 \mathrm{~d}$.

The numbers of displacements at the feed bunk, in the free stall, and at the mechanical brush were recorded through continuous observations of the same periods described above (DeVries et al., 2007; Val-Laillet et al., 2008). Displacements from each resource were summed over days and transformed into an initiator-receiver matrix with rows labeled as initiator and columns labeled as receiver and analyzed using MatMan (Noldus Information Technology, Wageningen, the Netherlands; de Vries, 1998). Based on Val-Laillet et al. (2008), these data were used to calculate a dominance index varying from 0 to 1 ; that is, the proportion of displacements an animal initiated at a specific resource compared with the total number of displacements in which the animal was involved at that resource as an initiator or as a receiver (Galindo and Broom, 2000; Galindo et al., 2000). The competitive index was used to measure the relationship between dominance and access to the resources to categorize all animals into 3 subgroups of dominance (Galindo and Broom, 2000): high-ranking animals (index $\geq 0.6$ ), middle-ranking animals $(0.4 \leq$ index $<0.6$ ), and low-ranking animals (index $<0.4$ ). The total access time to the resources was compared between these 3 categories and expressed the number of displacements as a function of access time.

Displacements were analyzed between resources using the Friedman test followed by the Wilcoxon test for pairwise comparisons. Ranking levels were compared using the Kruskal-Wallis test followed by the MannWhitney test. The competitive indices for cows at each resource were compared to determine whether cows achieve similar priority of access to the resources using Fisher's $\mathrm{r}$ to $\mathrm{z}$ test for correlations followed by the Bonferroni correction.

Time spent at the resources and displacements from these resources are in Table 1. Findings indicated that $63 \%$ of the possible pairings of cows (dyads) were not observed to competitively interact at any time in the lying area or at the mechanical brush. By comparison, only $6 \%$ of pairings did not interact at the feeder. Although cows spent very little time at the mechanical brush compared with the feeding or lying areas, the frequency of displacements was much greater than the other 2 resources when adjusted for time of use (Table 1). There was a significant correlation between feeder and stall competitive success $(\mathrm{r}=0.32, P<0.01)$. With the exception of brush usage $(\mathrm{r}=-0.35, P<0.01)$, there was no correlation between the competitive index of each resource and the time spent at these respective resources. No differences were detected between the 3 levels of social rank for the total time spent using each 
Table 1. Frequency of displacements (mean \pm SEM; \% in parentheses) at each resource as a function of the time spent at the resource

\begin{tabular}{|c|c|c|c|}
\hline Item & \multicolumn{3}{|c|}{ Resource } \\
\hline Total displacements/d & $\begin{array}{c}113.0 \pm 16.7^{\mathrm{a}} \\
(87.6 \pm 1.4 \%)\end{array}$ & $\begin{array}{l}12.0 \pm 1.7^{\mathrm{b}} \\
(9.5 \pm 1.2 \%)\end{array}$ & $\begin{array}{c}3.2 \pm 0.8^{\mathrm{b}} \\
(2.8 \pm 0.8 \%)\end{array}$ \\
\hline Displacements per cow/d as an initiator or receiver & $18.9 \pm 1.2^{\mathrm{a}}$ & $2.0 \pm 0.2^{\mathrm{b}}$ & $0.5 \pm 0.1^{\mathrm{b}}$ \\
\hline Time spent at the resource per cow/d (h) & $\begin{array}{c}5.6 \pm 0.1^{\mathrm{b}} \\
(23.3 \pm 0.5 \%)\end{array}$ & $\begin{array}{c}13.9 \pm 0.2^{\mathrm{a}} \\
(58.1 \pm 0.8 \%)\end{array}$ & $\begin{array}{c}0.12 \pm 0.01^{\mathrm{c}} \\
(0.5 \pm 0.04 \%)\end{array}$ \\
\hline Correlation displacements/time spent at the resource & $\begin{array}{l}\mathrm{r}=0.13 \\
P=0.28\end{array}$ & $\begin{array}{c}\mathrm{r}=-0.21 \\
P=0.07\end{array}$ & $\begin{array}{l}\mathrm{r}=-0.26 \\
P=0.032\end{array}$ \\
\hline
\end{tabular}

${ }^{a-c}$ Means within a row with different superscripts differ $(P<0.05)$.

${ }^{1}$ Mean obtained after removing 3 aberrant values (75, 480, and 540 displacements/h).

resource $(P>0.05)$. Yet there was an overall trend in time spent feeding $2 \mathrm{~h}$ post-fresh feed delivery between the 3 ranking levels (Kruskal-Wallis: $\mathrm{H}=5.69, P=$ 0.058). Cows in the high-ranking group spent a greater percentage of their time at the feeder compared with cows in the low ranking group (43.8 \pm 2.3 and $36.7 \pm$ $2.0 \%$, respectively; $\mathrm{z}=2.30, P=0.022)$. Cows in the middle-ranking groups were intermediate $(41.5 \pm$ $2.1 \%$ ) and did not differ from the other 2 groups. Low but significant correlations were found between milk production and competitive success at the feeder $(\mathrm{r}=$ $0.275, P=0.019)$ and at the brush $(\mathrm{r}=0.294, P=0.018)$, but not in the free-stalls $(\mathrm{r}=0.003, P=0.979)$.

Our results provide the first evidence that dominance is not consistent across the 3 resources available to dairy cows. Indeed, the measures of competitive success were not highly correlated between access to the feeder, to the free stalls, and to the mechanical brush. Under the conditions present, 88\% of all aggressive interactions took place in the feeding area, whereas $<10 \%$ took place at the stalls and $<3 \%$ at the mechanical brush. These results confirm what others (DeVries et al., 2004) observed: competition for feed is a major source of tension between intensively housed dairy cattle. This was probably the result of the high demand for food required for milk production (Phillips and Rind, 2002), combined with inadequate feeding space. Cows were provided $0.60 \mathrm{~m}$ of bunk space following standard recommendations (Grant and Albright, 2001), but this is likely inadequate for all cows to feed together. Increasing feed bunk space reduced aggressive behavior in cattle (Kondo et al., 1989) and increased access to feed, particularly for subordinate cows (DeVries et al., 2004; DeVries and von Keyserlingk, 2006; Huzzey et al., 2006). Although bedding quality in the stalls can decline over days when not properly maintained (Drissler et al., 2005), feed quantity and quality declined at a much faster rate with differences occurring throughout the course of the day (DeVries et al., 2005). This may explain the greater competition for this resource evident in the $2 \mathrm{~h}$ after provision of feed. Competition at the feed bunk was discriminatory as high-ranking cows spent more time at the feeder during the $2 \mathrm{~h}$ following provision of fresh feed than did low-ranking cows. De Vries et al. (2005) demonstrated that increases in the frequency of fresh feed delivery resulted in subordinate cows having more-equal access to feed throughout the day. Improving the supply of fresh feed during the day might improve social relationships, and thereby milk production, in dairy cows. Although this experiment was not designed to investigate the relation between rank and milk production, daily milk production was correlated to the competitive index at the feeder. This finding could indicate that reducing competition between cows could improve the production of lowranking cows, but further studies are encouraged to verify this finding.

In our experiment, the frequency of displacements per hour spent at the resource was the lowest for the stalls compared with the feeder and brush. This indicated that with 1 stall/cow the frequency of aggressive events was not a function of time spent at this resource. Cows spent approximately $58 \%$ of their time in the freestalls, which was similar to previous reports (Drissler et al., 2005; Fregonesi et al., 2007). Several aspects of the lying environment can influence the ability of cows to access the free-stalls, including the number of stalls available per animal and the physical design of the free-stall area. Competitive behavior for access to stalls increased when stocking increased above 1 cow per stall (Fregonesi et al., 2007). In the present study, cows were each provided with 1 partitioned lying space; thus, low-ranking cows were not required to engage in competitive behavior to gain access to a stall. DeVries and von Keyserlingk (2006) showed that the addition of partitions between feeding positions at the 
feed alley reduced the number of displacements at the feeder, particularly for subordinate cows. The partitions between free-stalls may have a similar effect. No differences were observed between animals or between ranking levels for the time spent in the stalls. Some researchers showed that even if there was no single stall preference, cows chose one side of the shed more than the other (Arave and Walters, 1980) and more frequently chose the stalls that were closer to the feeder (Gaworski et al., 2003).

Although cows only accessed the mechanical brush $<7 \mathrm{~min} / \mathrm{d}$ on average, they engaged in competitive behavior to gain access to it. Theoretically, an animal could easily fulfill its need to groom at the brush without having to compete for it, because the brush was free most of the time. Increasing the size of the group in a future experiment could help endorse this theory. When the number of displacements was considered as a function of the time spent at the resource, the frequency of aggressive interactions was greatest for access to the brush, even compared with the feeder. The brush was located opposite the water trough in a crossover alley frequently used by the cows. Thus, we hypothesize that the probability of being displaced by chance at the brush was likely greater than that of being displaced by chance at the feeder or in the stalls. Future work should focus on the location of the mechanical brush and other features in the pen to determine effects on usage.

Despite the possible lack of need for cows to actively compete for access to stalls and brush, it appeared that individual animals value different resources differently. Indeed, the indices of competitive success were only lowly correlated between resources, meaning that cows that were high ranking at the feeder did not have priority of access to the stalls or the brush. For example, several animals in the low-ranking group for the access to the feeder obtained a very high index of competitive success for access to the stalls; similarly, several animals in the high-ranking group for the access to the feeder obtained a very low index of competitive success for access to the stalls. This effect might be due to the existence of different strategies or degrees of motivation by cows using available resources. Some animals might choose to compete more and spend more time close to the resource for which their motivation was greatest. But there must be caution in this interpretation, because numerous dyads (possible pairs of animals) did not interact at all in the stalls or at the brush, making it impossible to draw conclusions about the dominance status in these dyads. It is possible that the classical view of dominance, asserting that there is one basic social order through which all of a group's resources were regulated (Syme, 1974), applied only when social tension and pressure for all the resources was sufficiently high.

In conclusion, the intensity of competition for different resources within the free-stall environment was not a function of the time spent at a resource, but rather a function of the specific motivation and social pressure present for that resource. In the context of our study, it was clear that competition for feed was the main source of aggressive interactions between cows. These results justify the necessity to improve the actual management systems to reduce competition at the feeder. These conclusions do not reduce the importance of competition for other resources, but highlight the necessity for further studies focusing on larger groups of animals or situations of overstocking, in which competition for other resources (e.g., lying areas) could be more important.

\section{ACKNOWLEDGMENTS}

We thank Marcella Vandova (Animal Welfare Program) and Audrey Nadalin (Agriculture and Agri-Food Canada) who made this work possible by participating in supervising the data recording. We thank Nelson Dinn and the farm staff at the UBC Dairy Education and Research Farm for the care they provided to the animals. The UBC Animal Welfare Program is funded by the Natural Sciences and Engineering Research Council of Canada and by contributions from the Dairy Farmers of Canada and many others listed at http:// www.landfood.ubc.ca/animalwelfare.

\section{REFERENCES}

Arave, C. W., and J. L. Walters. 1980. Factors affecting lying behavior and stall utilization of dairy cattle. Appl. Anim. Ethol. 6:369-376.

Canadian Council on Animal Care. 1993. Pages 31-44, 52-55 in Guide to the Care and Use of Experimental Animals. Vol. 2. E. D. Olfert, B. M. Cross, and A. A. McWilliams, ed. CCAC, Ottawa, Ontario, Canada.

Craig, J. V. 1986. Measuring social behavior: Social dominance. J. Anim. Sci. 62:1120-1129.

de Vries, H. 1998. Finding a dominance order most consistent with a linear hierarchy: A new procedure and review. Anim. Behav. 55:827-843.

DeVries, T. J., M. Vankova, D. M. Veira, and M. A. von Keyserlingk. 2007. Short communication: Usage of mechanical brushes by lactating dairy cows. J. Dairy Sci. 90:2241-2245.

DeVries, T. J., and M. A. G. von Keyserlingk. 2006. Feed stalls affect the social and feeding behavior of lactating dairy cows. J. Dairy Sci. 89:3522-3531.

DeVries, T. J., M. A. G. von Keyserlingk, and K. A. Beauchemin. 2005. Frequency of feed delivery affects the behavior of lactating dairy cows. J. Dairy Sci. 88:3553-3562.

DeVries, T. J., M. A. G. von Keyserlingk, and D. M. Weary. 2004 Effect of feeding space on the inter-cow distance, aggression, and feeding behavior of free-stall housed lactating dairy cows. J. Dairy Sci. 87:1432-1438. 
DeVries, T. J., M. A. G. von Keyserlingk, D. M. Weary, and K. A. Beauchemin. 2003. Measuring the feeding behavior of lactating dairy cows in early to peak lactation. J. Dairy Sci. 86:33543361.

Drews, C. 1993. The concept and definition of dominance in animal behaviour. Behaviour 125:283-313.

Drissler, M., M. Gaworski, C. B. Tucker, and D. M. Weary. 2005. Freestall maintenance: Effects on lying behavior of dairy cattle. J. Dairy Sci. 88:2381-2387.

Fregonesi, J. A., C. B. Tucker, and D. M. Weary. 2007. Overstocking reduces lying time in dairy cows. J. Dairy Sci. 90:3349-3354.

Galindo, F., and D. M. Broom. 2000. The relationships between social behaviour of dairy cows and the occurrence of lameness in three herds. Res. Vet. Sci. 69:75-79.

Galindo, F., D. M. Broom, and P. G. Jackson. 2000. A note on possible link between behaviour and the occurrence of lameness in dairy cows. Appl. Anim. Behav. Sci. 67:335-341.

Gaworski, M., C. B. Tucker, D. M. Weary, and M. L. Swift. 2003 Effects of stall design on dairy cattle behaviour. Pages 139-146 in 5th International Dairy Housing Conference, Fort Worth, TX

Grant, R. J., and J. L. Albright. 2001. Effect of animal grouping on feeding behavior and intake of dairy cattle. J. Dairy Sci. 84(E Suppl.):E156-E163.

Huzzey, J. M., T. J. De Vries, P. Valois, and M. A. G. von Keyserlingk. 2006. Stocking density and feed barrier design affect feeding and social behavior of dairy cattle. J. Dairy Sci. 89:126-133.

Kondo, S., J. Sekine, M. Okubo, and Y. Asahida. 1989. The effect of group size and space allowance on the agonistic and spacing behavior of cattle. Appl. Anim. Behav. Sci. 24:127-135.
Lobato, J. F. P., and R. G. Beilharz. 1979. Relation of social dominance and body size to intake of supplements in grazing sheep. Appl. Anim. Ethol. 5:233-239.

National Research Council. 2001. Pages 315-333 in Nutrient Requirements of Dairy Cattle. Natl. Acad. Press, Washington, DC.

Orihuela, A., and C. S. Galina. 1997. Social order measured in pasture and pen conditions and its relationship to sexual behavior in Brahman (Bos indicus) cows. Appl. Anim. Behav. Sci. 52:3-11.

Phillips, C. J., and M. I. Rind. 2001. The effects on production and behavior of mixing uniparous and multiparous cows. J. Dairy Sci. 84:2424-2429.

Phillips, C. J., and M. I. Rind. 2002. The effects of social dominance on the production and behavior of grazing dairy cows offered forage supplements. J. Dairy Sci. 85:51-59.

Phillips, C. J. C. 1993. Cattle behaviour. Farming Press Books, Ipswich, UK.

Rushen, J. 1984. How peck orders of chickens are measured: A critical review. Appl. Anim. Ethol. 11:255-264.

Soffié, M., G. Thines, and G. De Marneffe. 1976. Relation between milking order and dominance value in a group of dairy cows. Appl. Anim. Ethol. 2:271-276.

Syme, G. J. 1974. Competitive orders as measures of social dominance. Anim. Behav. 22:931-940.

Val-Laillet, D., A. M. de Passille, J. Rushen, and M. von Keyserlingk. 2008. The concept of social dominance and the social distribution of feeding-related displacements between cows. Appl. Anim. Behav. Sci. 111:158-172. 